\title{
Magnetic Field Dosimeter Development
}

\author{
D. K. Lemon \\ J. R. Skorpik \\ J. L. Eick
}

September 1980

Prepared for the U.S. Department of Energy under Contract DE-AC06-76RLO 1830

Pacific Northwest Laboratory Operated for the U.S. Department of Energy by Battelle Memorial Institute 
NOTICE

This report was prepared as an account of work sponsored by the United States Government. Neither the United States nor the Department of Energy, nor any of their employees, nor any of their contractors, subcontractors, or their employees, makes any warranty, express or implied, or assumes any legal liability or responsibility for the accuracy, completeness or usefulness of any information, apparatus, product or process disclosed, or represents that its use would not infringe privately owned rights.

The views, opinions and conclusions contained in this report are those of the contractor and do not necessarily represent those of the United States Government or the United States Department of Energy.

\author{
PA.CIFIC NORTHWEST LABORATORY \\ operated by \\ BATTELLE \\ for the \\ UNITED STATES DEPARTMENT OF ENERGY \\ Under Contract DE-AC06-76RLO 1830
}

\author{
Printed in the United States of America \\ Available from \\ National Technical Information Service \\ United States Department of Commerce \\ 5285 Port Royal Road \\ Springfieid. Virginia 22151
}

Price: Printed Copy 5

$\because$ Microfiche 53.00

$\begin{array}{cc}\text { •Pages } & \begin{array}{c}\text { NTIS } \\ \text { Selling Price }\end{array} \\ 001-025 & \$ 4.00 \\ 026-050 & \$ 4.50 \\ 051-075 & \$ 5.25 \\ 076-100 & \$ 6.00 \\ 71-125 & \$ 650 \\ 126156 & \$ 15 \\ 151-175 & \$ d) 0 \\ 176-200 & \$ 9.00 \\ 201-225 & \$ 9.25 \\ 226-250 & \$ 9.50 \\ 251-275 & \$ 10.75 \\ 276-300 & \$ 11.00 \\ & \end{array}$




\section{1}

MAGNETIC FIELD

DOSIMETER DEVELOPMENT

D. K. Lemon

J. R. Skorpik

J. L. Eick

September 1980

Prepared for

the U.S. Department of Energy

under Contract DE-AC06-76RLO 1830

Pacific Northwest Laboratory

Richland, Washington 99352 
TABLE OF CONTENTS

Page

$\begin{array}{lc}\text { OVERVIEW } & 1 \\ \text { APPROACH } & 1 \\ \text { FUNCTION } & 10 \\ \text { COMPUTATION OF DOSE } & 11 \\ \text { CALIBRATION PROCEDURE } & 13 \\ \text { CONCLUSIONS AND RECOMMENDATIONS } & 14 \\ \text { APPENDIX I: SAMPLE OPERATING PROCEDURE } & 16 \\ \text { APPENDIX II: DETAILED DESCRIPTION OF INSTRUMENTS } & 21\end{array}$ 
.

. 
MAGNETIC FIELD DOSIMETER

Theory of Operation and Instruction Manual

\section{OVERVIEW}

In recent years there has been increased concern over potential health hazards related to exposure of personnel to magnetic fields. If exposure standards are to be established, then a means for measuring magnetic field dose must be available. To meet this need, the Department of Energy has funded development of prototype dosimeters at the Battelle Pacific Northwest Laboratory. This manual reviews the principle of operation of the dosimeter and also contains step-by-step instructions for its operation.

It should be noted that the dosimeters described herein are not intended for immediate field use. Recent advances in solid state circuitry would allow a second generation dosimeter to have even longer life and greater capability. The primary purpose of these dosimeters is to demonstrate feasibility and point the way for future refinements, evaluation and field testing.

\section{APPROACH}

The approach used for the dosimeter data recording system is shown in Figure 1. The basic sensing elements are three Hall Effect sensors that are oriented perpendicular to one another. They are connected to 


\section{APPROACH}

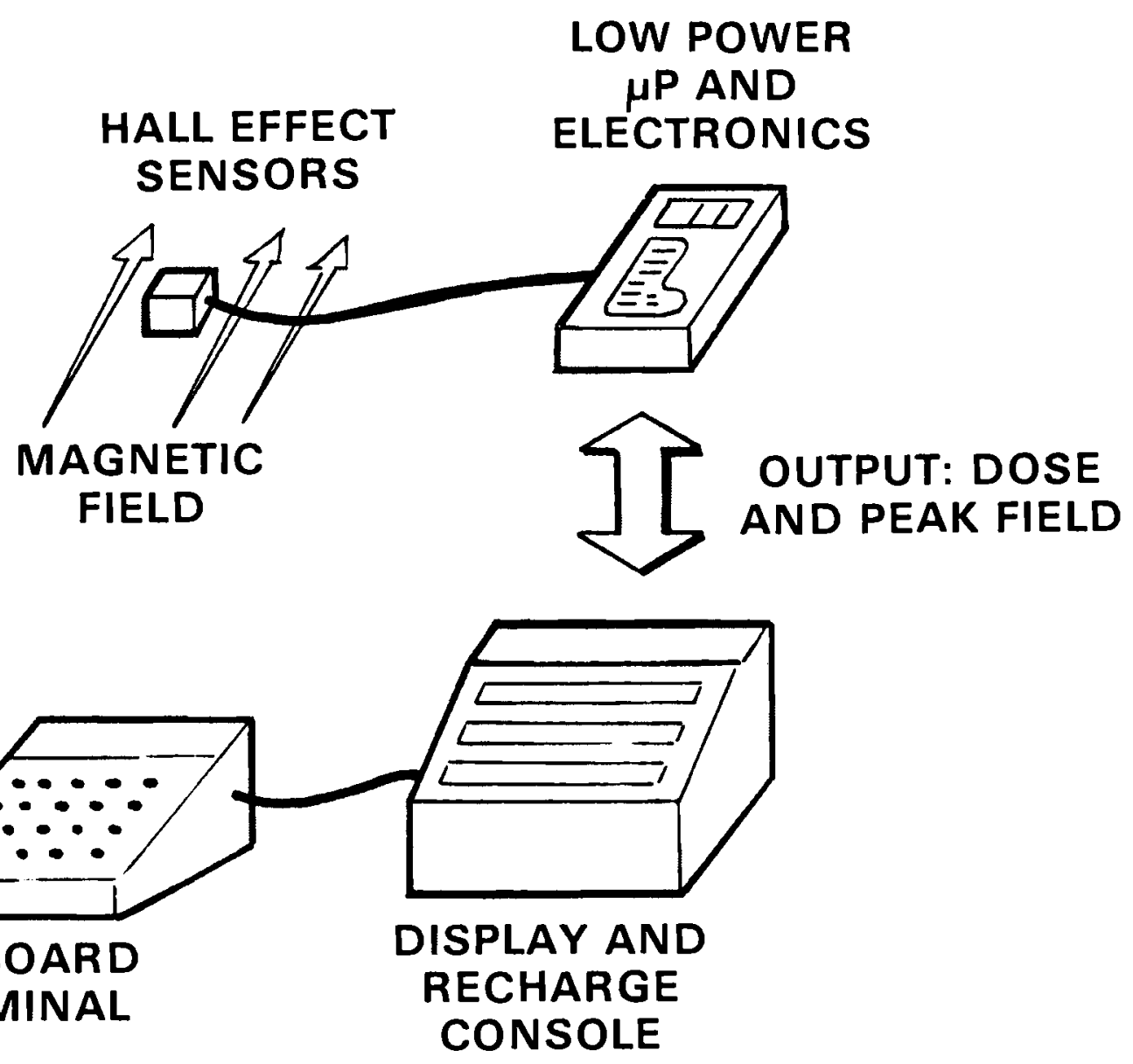

Figure 1. Diagram of the approach used in the magnetic field dosimeter data recording system 
the body of the dosimeter with an umbilical cord. The Hall sensors measure three components of the magnetic field $B_{x}, B_{y}$ and $B_{z}$, thereby uniquely defining the field. The measurements obtained from the Hall sensors are sampled cyclically by a microprocessor in the dosimeter. During an operation period the dosimeter stores the dose information for subsequent readout. At the end of a measurement period (a work day for example), the dosimeter is connected to a Data Recording Console. The worker types in his name at the teletype and the dosimeter data is read out into the console. A microprocessor in the console then reduces the dose information and prints it out on the teletype unit. A sample printout is shown in Figure 2. In actual field applications a cassette tape unit would also be used to permanently record the dose information for each individual. Through a cassette recorder, data on a large number of individuals could be recorded and later retrieved for analysis.

The completed dosimeter system is shown in Figures 3 through 6 . The entire system is shown in Figure 3. The readout console is on the right and the teletype unit is shown on the left. The two dosimeters are in the center. Figure 4 shows how, at the end of a work period, a worker would plug his dosimeter into the console and enter his name on the teletype, thereby recording his day's dose. This process for each person would take two minutes or less. Close-up photographs of the dosimeter are shown in Figures 5 and 6 . In Figure 5, the handheld size of the device is illustrated. Figure 6 shows the internal circuitry of the dosimeter. 


\section{MAGHETIE FIELI EMFQSIFE IIATA}

\section{IIFTE:}

HAME:

TOTFL EMFOIIFE TIME:

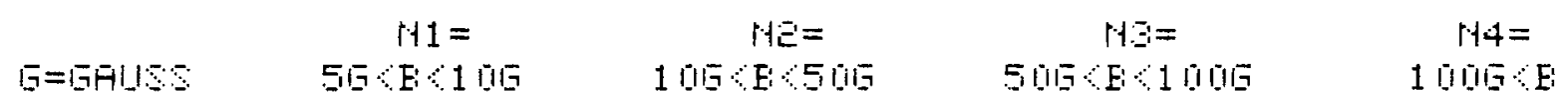

PWMEEF:

DF

SANFLES

01010010

101010

101010

001010

IIDSE

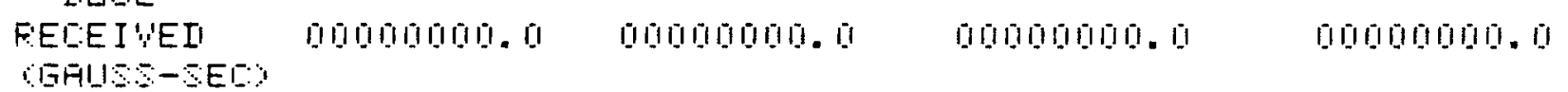

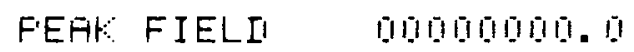

Figure 2. A sample teletype printout of the dose information recorded for each individual at the end of a working period. 


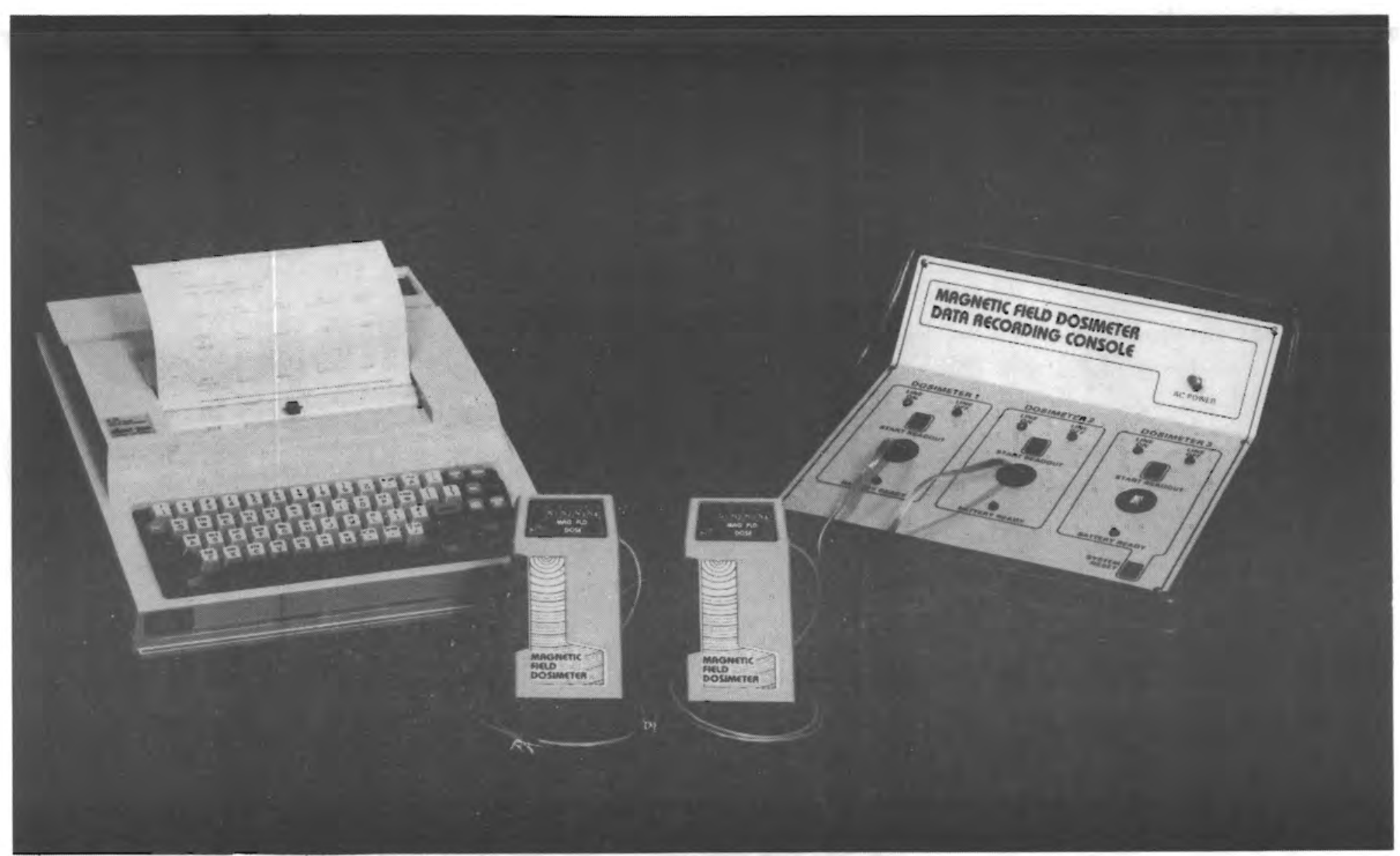

Figure 3. Photograph of the entire dosimeter system showing the readout console (right), teletype (left) and dosimeters (center). 


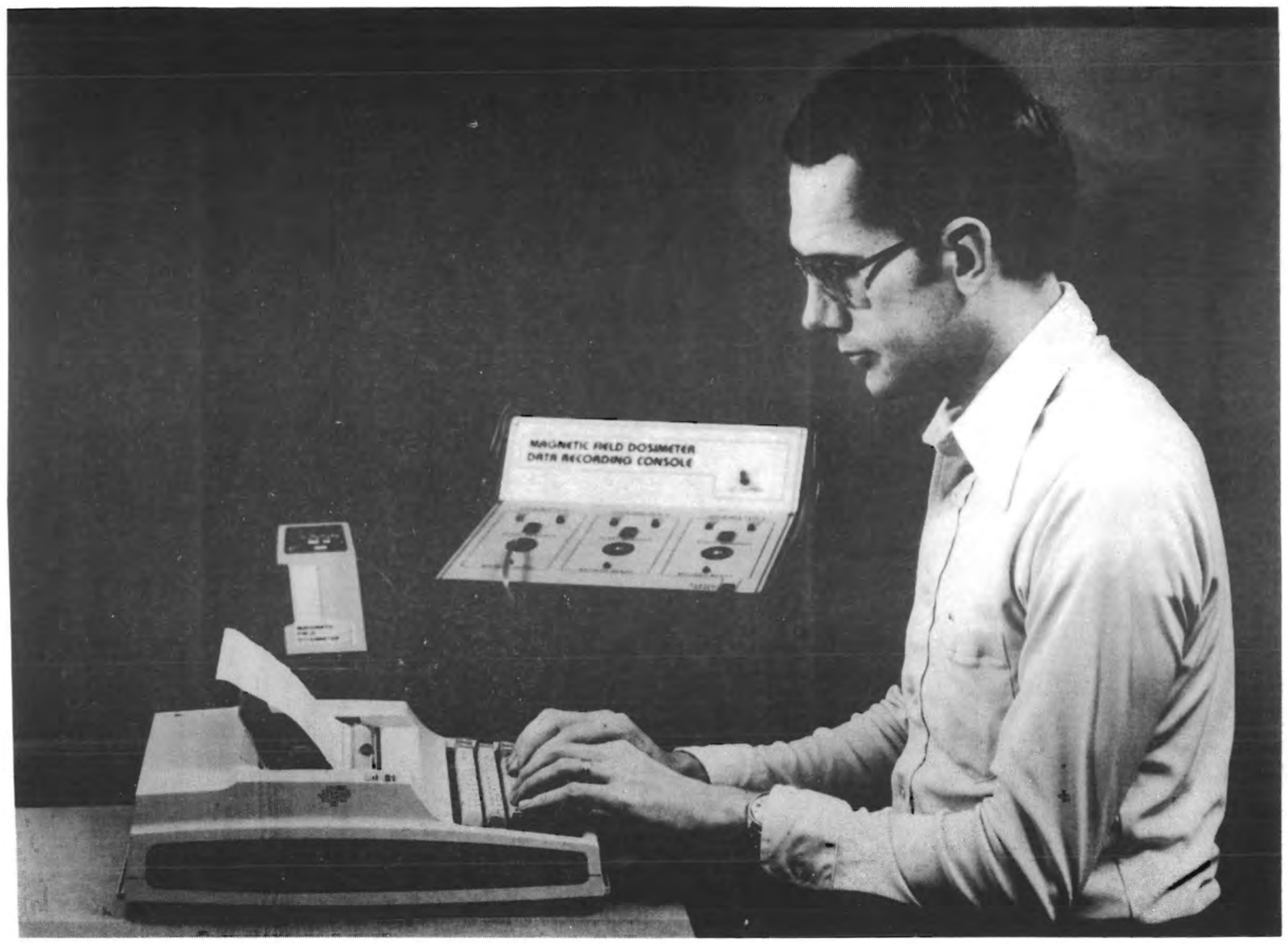

Figure 4. Photograph depicting a worker logging in his dosimeter at the end of a work period. 


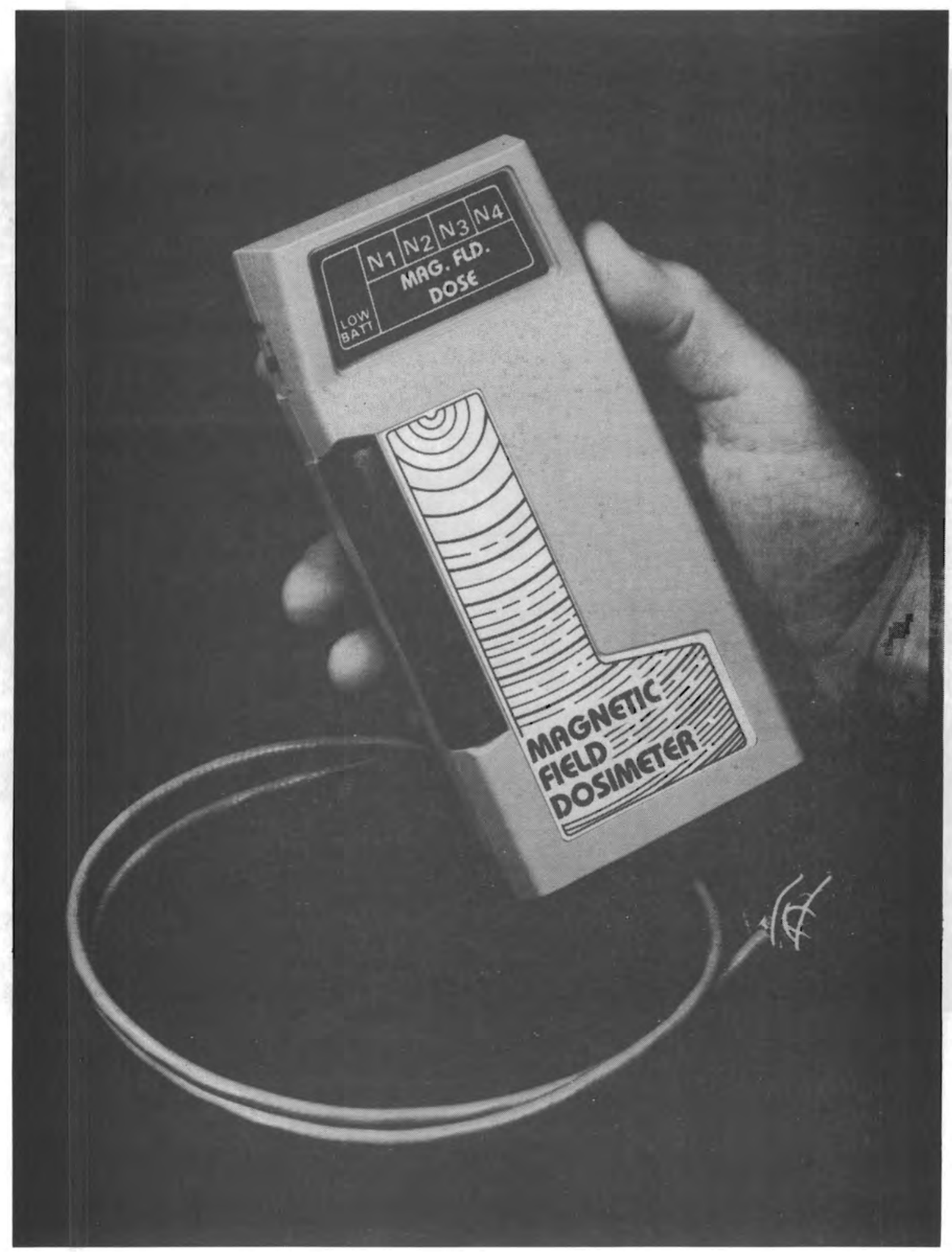

Figure 5. A close-up photograph of a dosimeter. 


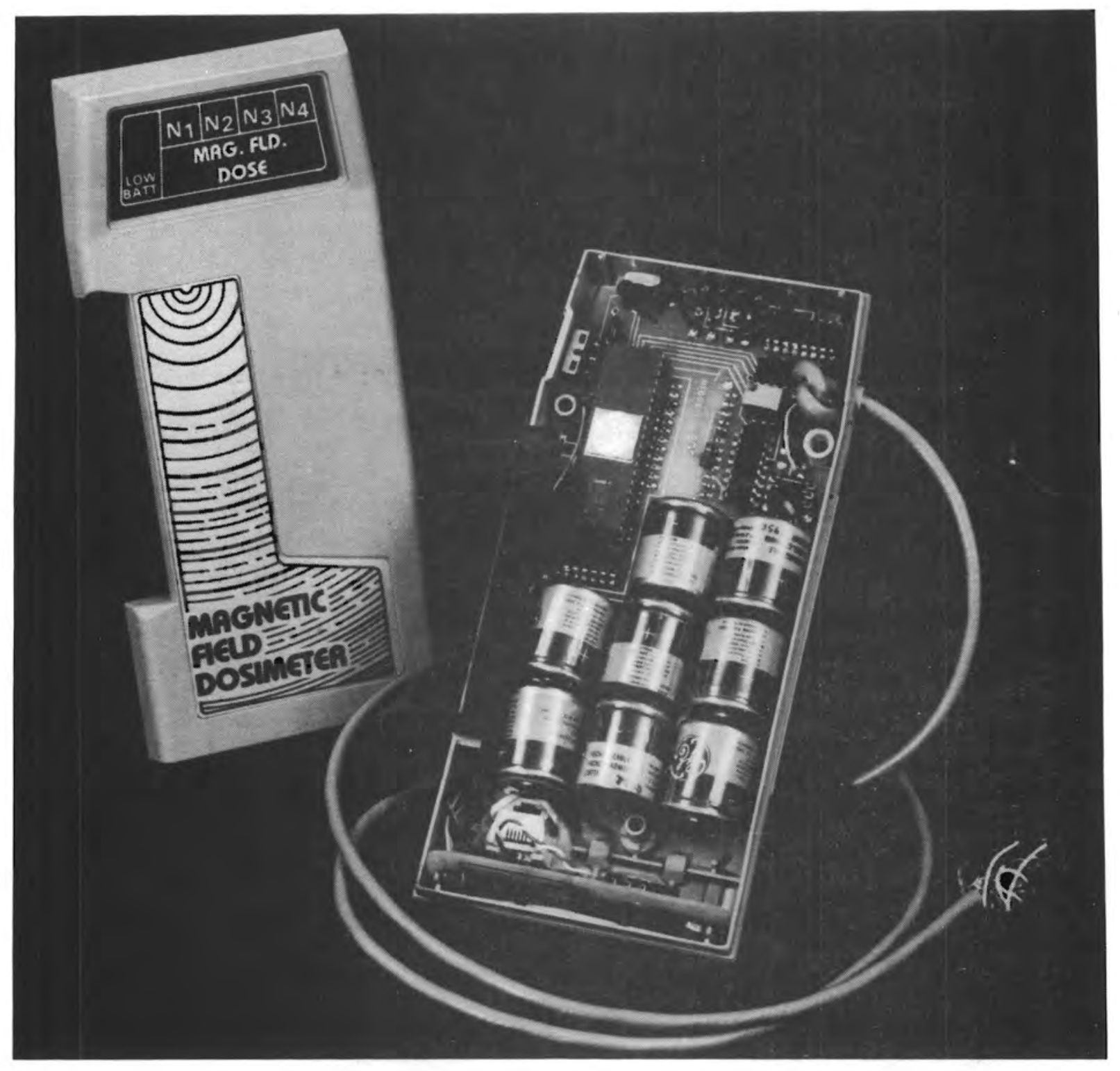

Figure 6. A view of the internal circuitry of a magnetic field dosimeter. 


\section{MAGNETIC FIELD DOSIMETER BLOCK DIAGRAM}

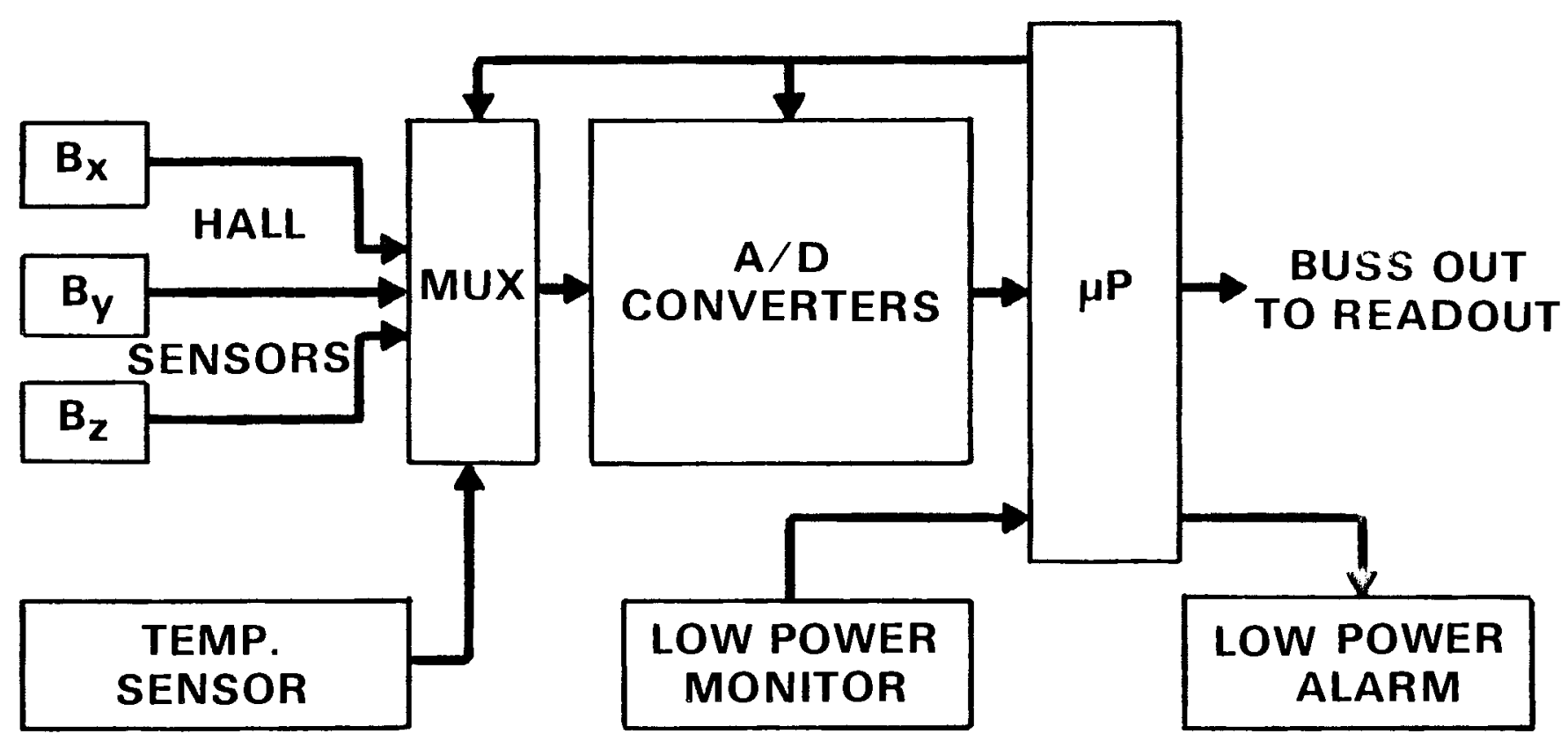

Figure 7. A block diagram of the dosimeter. 


\section{FUNCTION}

The function of the dosimeter is described in this section in a narrative way. Figure 7 is a basic block diagram of the dosimeter.

When the dosimeter is first powered up it automatically goes into a five minute warm-up period before dose is accumulated. At the end of the warm-up period, the microprocessor samples the voltages on the three Hall sensors corresponding to the three components of the magnetic field, $B_{x}, B_{y}$ and $B_{z}$. These voltages are used as the "zero field" reference voltages for that measurement period. Thereafter, the dosimeter accumulates the dose by sampling the Hall sensors three times per second. For each sample, the quantity $B_{i}{ }^{2}=B_{x}{ }^{2}+B_{y}{ }^{2}+B_{z}{ }^{2}$ is computed and added to all previous $B_{i}{ }^{2}$ measurements, i.e.,

$$
T^{2}=\sum_{i=1}^{N} B_{i}{ }^{2} .
$$

The cumulative $\mathrm{T}^{2}$ values are stored for four field strength ranges. The quantity $\mathrm{T}_{1}{ }^{2}$ is for field strength from 5 to $10 \mathrm{~g}$ ( $\mathrm{g}=$ gauss). Likewise $N_{1}$ is the number of samples involved in computing $T_{1}^{2}$. Similarly, the second field strength range is $10 \mathrm{~g}<\mathrm{B}_{\mathrm{j}}<50 \mathrm{~g}$ corresponding to $\mathrm{T}_{2}{ }^{2}$ and $\mathrm{N}_{2}$; the third range is $50 \mathrm{~g}<\mathrm{B}_{\mathrm{i}} \leq 100 \mathrm{~g}$, and the fourth range is for $B>100 \mathrm{~g}$. Storing the dose by ranges of field strength gives the analyst much more information regarding the field strengths encountered. This technique helps remove the inherent ambiguity between a dose received by a small field over a long time 
period and the same dose received by a large field over a short time. Hence during the course of an operating period, the dosimeter continually updates the values of $\mathrm{N}_{1}-\mathrm{N}_{4}$ and $\mathrm{T}_{1}{ }^{2}-\mathrm{T}_{4}^{2}$.

The maximum magnetic field encountered is also recorded and updated automatically. This is done by comparing each value of $B_{i}{ }^{2}$ with the previous maximum value, and saving the larger value.

At the end of a working period, the individual returns the dosimeter to the data recording console. A single cord connecting the dosimeter and console provides a data link and means of recharging the dosimeter batteries. The operator then presses the START READOUT button to initiate a readout process. To complete the process, he then enters his name on the teletype terminal.

COMPUTATION OF DOSE

The "dose of magnetic field" received, in the conventional meaning of dosage, is given by

$$
\text { Dose }=(\text { Average Magnetic Field) } \times \text { (Total Exposure Time) }
$$

For $N$ discreet measurements of the field strength, the dose is described mathematically as

$$
D_{\ell}=\left(\frac{1}{N} \sum_{i=1}^{N} B_{i}\right) \times(N \Delta t)=\Delta t \sum_{i=1}^{N} B_{i}
$$


where $\Delta t$ is the sampling period. We have denoted the dose as $D_{\ell}$ where the subscript " $\ell$ " means linear dose. A linear dose simply means that the dose depends linearly on the field strength, i.e., the dose varies as the first power of $B$.

The magnetic field dosimeter described in this manual measures a quadratic dose - or a dose that is weighted by the square of the field strength. This was necessary because performing a square root function in the dosimeter microprocessor was impractical due to overall program memory size constraints. The square root had to be performed by the readout console. New microprocessors now on the market would allow a linear dose to be computed.

The quadratic dose is described as

$$
\left.D_{q}=\text { (Square Root of the Average Value of } B^{2}\right) \times \text { (Exposure Time) }
$$

or mathematically

$$
D_{q}=\left(B^{2}\right)_{a v e}^{1 / 2} \times N \Delta t
$$

For $N$ samples over a time interval, we have

$$
D_{q}=\left(\frac{1}{N} \sum_{i=1}^{N} B_{i}^{2}\right)^{1 / 2} \times N \Delta t
$$


or $D_{q}=\left(N \sum_{i=1}^{N} B_{i}^{2}\right)^{1 / 2} \Delta t$

By defining $T^{2}=\sum_{i=1}^{M} B_{i}^{2}$ then Equation (6) becomes

$$
D_{q}=\left(N T^{2}\right)^{1 / 2} \Delta t
$$

It should be pointed out that if the field is a constant, $B_{0}$, for all $\mathrm{N}$ samples, then the linear and quadratic dose both reduce to the linear dose of $\mathrm{B}_{0} \mathrm{~N} \Delta \mathrm{t}$ as can be seen from Equations (2) and (6).

The effect of the quadratic dose is to weight the higher fields more strongly in the final dose value. If, for example, biological effects

were proportional to $B^{2}$ rather than $B$, then the quadratic dose would be the more appropriate. Physically, the magnetic field energy density is proportional to $B^{2}$. So the quadratic dose is a measure of the exposure to the total magnetic field energy.

\section{CALIBRATION PROCEDURE}

The calibration of a magnetic field dosimeter is not a simple task. As field-ready dosimeters are developed, calibration procedures suitable for the field will have to be addressed more thoroughly. The dosimeters developed on this project were calibrated in the following way. Three permanent magnets were obtained that had magnetic fields of $45 \mathrm{~g}, 95 \mathrm{~g}$ and $172 \mathrm{~g}$. The fields at a rigidly defined point were measured with a calibrated gaussmeter. Each Hall sensor was then placed at the prescribed point and its output voltage was recorded. 
This was repeated 10 times for each Hall sensor. In this way, a conversion factor of millivolts-to-gauss is obtained.

It is envisioned that for field applications a calibration technique would have to operate with completely fabricated dosimeters. This would require having a uniform magnetic field into which the Hall sensor head could be placed. Obtaining a uniform field over several cubic inches requires magnets with large surface areas. However, this procedure could be established in subsequent development work.

\section{CONCLUSIONS AND RECOMMENDATIONS}

This project has reached the objectives originally set forth, i.e., to develop working models of a magnetic field dosimeter. The dosimeter provides information on dose (in gauss-seconds) and the maximum magnetic field encountered. The dosimeter's measurements are not dependent on the orientation of the instrument to the field, hence an unambiguous mea surement is provided.

We conclude from this project that the Hall effect-microprocessor design is feasible for dosimeters in field use. The working models have shown that the problem of temperature compensation, voltage drift and electronic storage of the data can be adequately dealt with. During this project, investigations were made into alternative approaches for a dosimeter. In particular, designs that would allow several weeks of continuous operation were sought for. Unfortunately, no concepts were 
found that promised to offer long-term, unattended operation. Therefore, we conclude that the Hall effect-microprocessor approach is the one that should be pursued in future development.

Based on this project's progress and recent advances in low power microprocessors, we make the following recommendations:

- The present dosimeters should have limited field testing to further determine changes that should be made in future models. In particular, "human engineering" factors should be considered.

- The dosimeters should be altered to employ one of the new, low power microprocessors now on the market. Doing so would double the battery 1 ife (to 12 hours) and also allow greater flexibility in the computation of dose.

- A re-designed dosimeter should then be field hardened through a series of field tests and design improvements.

After these design and testing tasks are completed, a limited number of the dosimeters (perhaps one hundred) could be produced and deployed in the field. 


\section{APPENDIX I}

\section{SAMPLE OPERATING PROCEDURE}

1. Turn power "on" to teletype.

2. Turn power "on" to recording console.

- When power is turned on to the console, the teletype will respond with the following heading:

MAGNETIC FIELD EXPOSURE DATA

DATE:

- Carriage will pause after printing DATE:; the date can then be typed in followed by depressing the return button on the teletype. Carriage will then return to the left margin and await a data recording sequence. 
3. STide the POWER ON-OFF switch on the bottom rear of the dosimeter to the OFF position. This will prepare the dosimeter for a battery charge/check sequence.

Connect the dosimeter to the recording console by way of the short gray umbilical cord with phone plugs at either end.

4. Check BATTERY READY light at this station. If BATTERY READY light is "on," it is safe to proceed; a full battery life (6 hours) can be expected; otherwise exact battery life is unknown.

5. Disconnect gray cable from dosimeter before sliding dosimeter POWER ON-OFF switch to ON. Also be certain the POWER SAVER ON-OFF switch is in the OFF position before turning dosimeter power ON.

6. Slide the dosimeter POWER ON-OFF switch to ON. Al1 5 lights in the front display will flash momentarily. Lights $N_{7}$ and $N_{4}$ will next alternately flash for approximately 5 minutes. During this "warm-up time" no dose samples can be taken. In fact, it is imperative that the dosimeter not be taken into an area in which magnetic field exposure is of concern until these lights stop flashing. The reason is that the first sample taken after the lights stop flashing is used as a background (zero magnetic field) reference reading. A11 subsequent samples are then measured against this reference sample value. 
7. After awaiting the prescribed "warm-up time," dosimeter operation can be tested by bringing the sensor package close to a test magnet. Depending on the strength of the field encountered (which will be a function of the magnet and the distance between the magnet and the sensor package), one of the four $\left(N_{1}, N_{2}, N_{3}\right.$ or $\mathrm{N}_{4}$ ) lights will flash with each sample. Samples are taken at the rate of three per second.

8. To read out the dosimeter, connect it again to the recording console via the gray umbilical cord and depress the START READOUT button on the console. Data in the dosimeter is transferred immediately to the console and the teletype responds with:

NAME:

The name of the wearer is then typed in followed by RETURN.

The console then responds with:

TOTAL EXPOSURE TIME:

Appropriate time can be entered in any format. This is strictly an informational item and is not used in any of the internal data calculations. Follow the time entered with RETURN. 
9. The teletype responds with the following heading:

\begin{tabular}{|c|c|c|c|c|}
\hline & $N_{1}=$ & $\mathrm{N}_{2}=$ & $N_{3}=$ & $N_{4}=$ \\
\hline$G=$ gauss & $5 G<B<10 G$ & $10 G<B<50 G$ & $50 G<B<100 G$ & $100 G<B$ \\
\hline
\end{tabular}

$B$ is the field strength level per sample.

The number of samples in each field strength range and the dose received is then printed out under each range.

Finally the peak field strength is printed out. This is the maximum single field strength experienced.

10. After the peak field is printed out, the recording console will automatically complete the readout sequence by turning off the LINE ON light and turning on the LINE OFF light.

11. The dosimeter POWER ON-OFF switch can be turned OFF. If the dosimeter is kept plugged in, the battery charge sequence will commence.

12. Low Battery Feature

As was mentioned earlier, useable battery life from full charge to low battery condition is approximately 6 hours. The battery voltage is monitored constantly and when it falls below a preset level, 
a signal is sent to the microprocessor which puts it into a low battery hold condition. At this time, no more dose samples are taken and the LOW BATT light is flashed. It should be noted that the operator/wearer has approximately 30 minutes to have the dosimeter read out before the data is lost due to battery failure.

AFTER the dosimeter is in the low battery hold condition, the power saver feature may be initiated. To do this, slide the POWER SAVER switch to the ON position. In this position no lights will flash and power consumption is reduced by approximately $20 \%$. This action will give the operator/wearer additional time beyond the 30 minutes before battery failure. The exact length of this extension depends on how quickly the power saver feature is activated after the low battery hold condition is entered. In any event, the power saver feature need not be activated before the data readout sequence is started.

CAUTION! If the power saver feature is activated, turning if oFF again may cause the data in memory to be altered. Therefore, if activated, keep the power saver on until after the dosimeter is read out in the normal procedure as outlined in Step 8 above. 


\section{APPENDIX II}

\section{DETAILED DESCRIPTION OF INSTRUMENTS}

This appendix describes in detail each component of the dosimeter system: i.e., the dosimeter, the readout console, and the teletype.

The function of each switch is described and the function of each light is explained. 
Magnetic Field Dosimeter (refer to Figure 4)

Controls:

POWER ON-OFF - Bottom rear of dosimeter package.

1. Disconnects battery power to dosimeter circuitry , and microprocessor.

2. Connects battery to jack for external readout/ charger plug.

POWER SAVER ON-OFF - Left side of dosimeter package just above black bar.

1. Disconnects battery power to all circuitry except microprocessor (to be used only in low battery condition).

Display:

${ }_{-1}^{N}$ LIGHT - Indicates dose readings in the 5-10 gauss range. $\mathrm{N}_{2}$ LIGHT - Indicates dose readings in the 10-50 gauss range. $\mathrm{N}_{3}$ LIGHT - Indicates dose readings in the 50-100 gauss range. $N_{1}$ LIGHT - Indicates dose readings in the $>100$ gauss range. LOW BATT LIGHT - When flashing, indicates dosimeter has ceased taking dose samples due to imminent battery 
failure. Operator has approximately 30 minutes to plug into readout/charger and initiate recording sequence before battery level drops too low and all data is lost! Battery life, from initial power on to low battery condition, is approximately 6 hours.

Magnetic Field Dosimeter Data Recording Console (refer to Figure 2)

Controls:

AC POWER - Turns power on to console $(110 \mathrm{~V} 60 \mathrm{~Hz})$. AC POWER pushbutton is lit when power is $0 \mathrm{~N}$.

START READOUT SWITCH - After dosimeter is plugged into appropriate jack on front panel, depressing this switch initiates data recording sequence. Data is transferred ( $<$ l second) from the dosimeter to the console immediately after switch is depressed.

SYSTEM RESET - Resets data recording console to initial power ON condition. Teletype will print out a new header.

Indicators:

LINE ON LIGHT - Indicates that a data readout sequence is in progress or is pending the completion of another 
previously initiated readout sequence. It will go "out" automatically upon completion of its readout sequence.

LINE OFF LIGHT - Indicates a data readout sequence is not in progress at that station. It will go "out" immediately upon initiation of a data readout sequence and will relight immediately upon completion of a data readout sequence.

BATTERY READY LIGHT - Indicates the charge status of the battery in the dosimeter connected to the associated station as follows:

Battery Ready Light "ON" - Battery fully charged. Battery Ready Light "OFF" - Battery is still charging.

Time to charge a battery which is in a LOW BATT condition in the dosimeter until the BATTERY READY light comes on is approximately 14 hours.

Texas Instruments Silent 700 Data Terminal (Teletype) Setup Instructions

Active Controls:

UPPER CASE - Can be switched to UPPER CASE (left) or LOWER CASE (right.) 
HALF DUP - Must be switched to FULL DUPLEX (switch to right).

LOW SPD - Must be switched to HIGH SPEED (switch to right). Data sent to terminal at 300 Baud rate.

ON LINE - Must be switched to ON LINE (switch to left) for operation with data recording console. May be switched OFF LINE (switch to right) for typing information without affecting recording console.

RETURN KEY - Orange key on keyboard

- In OFF LINE mode, returns print head (carriage) to left margin.

- In ON LINE mode, prompts data recording console to continue with readout sequence when depressed at the end of a typing sequence, for example:

NAME: Any information may be typed here followed by RETURN - readout sequence continues with:

TOTAL EXPOSURE TIME: Again, any information may be typed here followed by RETURN - readout sequence continues to end, unaffected by any terminal keystroke except PAPER ADVANCE. 


\section{CARRIER DETECT INDICATOR - (green light below ON LINE switch) - Will be on any time data recording console is connected to the data terminal and console power in 0N. Will go "Off" when console power is OFF.}

Full operating instructions for the data terminal are included in the Silent 700 - Model 743 KSR Data Terminal Operating Manual, included with the system. 


\section{DISTRIBUTION}

No. of

Copies

\section{OFFSITE}

A. A. Churm

DOE Patent Division

9800 S. Cass Ávenue

Argonne, IL 60439

DOE Division of Biomedical

and Environmental Research

Washington, DC 20545

27 DOE Technical Information Center

10 Dr. Robert W. Wood

Office of Health and

Environmental Research

Department of Energy

Washington, DC 20545

ONSITE

DOE Richland Operations Office

H. E. Ransom

22 Pacific Northwest Laboratory

A. M. Sutey

J. M. Nielsen

G. J. Posakony

D. K. Lemon (10)

J. R. Skorpik (2)

J. L. Eick (2)

D. L. Lessor

S. R. Doctor

D. D. Mahium (3)

Publishing Coordination (2)

Technical Information (5) 
1 